\title{
Role of field veterinarian in protected wild life region
}

\begin{abstract}
The role of field veterinarian in protected wild life region like national parks, wild life sanctuaries, biosphere reserves, tiger reserves, conservation reserve, community reserve, and other areas is to be understood in a wider angle rather than a narrow base. The technical expectation from the field veterinarian amount to a greater extent in recent days and hence it become crystal clear that the newly deputed veterinarians from the Animal Husbandry department should recognize their specific responsibilities expected by forest managers. So, keeping this in view some important information related to protected wild life are presented in this paper.
\end{abstract}

Volume 3 Issue 2 - 2018

\author{
Basant Bais \\ Rajasthan University of Veterinary and Animal Sciences, India
}

Correspondence: Basant Bais, Department of Livestock Products Technology, College of Veterinary and Animal Sciences, Rajasthan University of Veterinary and Animal Sciences, Bikaner, Rajasthan, 33400I, India, Email basantbais@gmail.com

Received: October 28, 2017 | Published: March 13, 2018

\section{Wild animals of concerned protected regions}

The information about specific wild animal species in the area should be gathered by interaction with personnel of different cadre in forest department. Additionally the wild animal species which is focused in that area should be known, e.g.Tiger is the much focused wild animal in tiger reserve area.

\section{Vegetation}

The major vegetation that serves as specific feed resources to the available herbivores should be identified and a review should be conducted periodically. The feed preferences should be noticed for specific wild animal species and also the seasonal availability of that feed in that area.

\section{Water resources}

Veterinarian should also know about the water needs of the concerned wild animal species and the problems in availability of water in deranged monsoon periods or summer seasons to undertake the crisis management measures during water scarcity periods. Highly contaminated water bodies should be identified.

\section{Information on domestic animals in surrounding areas}

The Veterinarian should know about the census figures and the dominant ruminants of that area and in the fringe villages surrounding the protected wild life regions.

Disease outbreaks in domestic animals in fringe villages of the protected areas

The veterinarian should know on the following.

a. The probable occurrence of specific disease

b. The area that is vulnerable for the specific disease outbreak

c. The species affected often by concerned disease outbreak d. Mortality rate

e. Morbidity rate

f. Symptomatology

g. Pathological lesions which may help for a fast clinical decisions.

\section{Coordination with veterinary and biological institutions}

Research is the basis for scientific management of any protected wild life regions and hence the veterinarian should have no hesitation in approaching veterinary and biological institutions to use the available expertise for welfare and conservation measures of wild animals.

\section{Biological information}

The field veterinarian should know the biological information on the concerned species e.g. Barasingha deer prefer tall grass for good breeding potential and success. Ecological relationship with health status should be understood in detail. E.g. non-human e.g. Cynomolgus macaques, Rhesus macaques etc. Primates live in groups but tiger or panther may be solitary and wild dogs live in packs.

\section{Information on chemical immobilization}

Immobilization is the most expected responsibility from wildlife veterinarian hence he should have knowledge on specific drug combination and their mode of action. E.g. ketamine is adequate for nonhuman primates like rhesus macaque, bonnet macaque where as xylazine in combination with ketamine is required for immobilization of felids.

\section{Capture of menace causing wild animals}

Before attempting for the capture of menace causing wild animals like tiger, panther, hyena, bear etc. the wild life veterinarian should plan meticulously on following. 
a. Biological aspects of concerned targeted species

b. Immobilization technique

c. Transport modes of captured animals

d. Health assessment measures to be taken after capture.

e. Samples to be taken and preservatives to be added transport containers etc.

f. Tranquilizers that may be used during long distance transport.

\section{Wild life health centre}

A wild life health centre should be established at the protected region and the centre should have the following:

a. Preservatives for the organs collected

b. Containers for transport of samples

c. Emergency medicines like doxapram hydrochloride, dexamethasone, antibiotics, atropine sulphate, intravenous fluids.

d. Immobilization equipments like blow pipe, pistol

e. Immobilization medicaments-xylazine, ketamine, Yohimbine, atropine etc.

f. Tranquilizers useful during transportation

g. First aid items like bandages, plasters, adhesive tapes, adrenaline, povidone iodine solution, antibiotic ointment, ropes of varying thickness h. Squeeze cages

i. Trap cages

j. Jab stick, syringe, needles, cotton

k. Refrigerator

\section{Health assessment in wild animals}

Random assessment of health in selected wild animals species shall be carried out whenever opportunities arises or when it demands in a periodical way. During transportation or shifting from one region to another health assessment measures should be undertaken. Whenever any lesion is fond sincere efforts should be undertaken to send samples in nearby institutions. He should prepare the list of diseases that can occur in focused wild animal and should be kept ready for a review. An enquiry on specific outbreak of any disease in livestock of nearby villages shall be made. He should observe on morbidity and mortality on specific species. Proper sampling and getting the confirmatory reports are the prime responsibilities of veterinarian and once the disease found out the precautionary measures shall be undertaken.

\section{Acknowledgements}

None.

\section{Conflict of interest}

Author declares there is no conflict of interests. 